\title{
Impacto dos agrotóxicos na alimentação: Uma revisão de literatura
}

\author{
Impact of pesticides on food: A literature review \\ Impacto de los plaguicidas en los alimentos: Revisión de la literatura
}

Recebido: 31/03/2021 | Revisado: 10/04/2021 | Aceito: 16/05/2021 | Publicado: 02/06/2021

Ana Karoline de Miranda Noblat
ORCID: https://orcid.org/0000-0002-0403-5740
Centro Universitário São Miguel, Brasil
E-mail: knoblat@ hotmail.com
Evaneide Maria da Silva Melo
ORCID: https://orcid.org/0000-0002-1359-4528
Centro Universitário São Miguel, Brasil
E-mail: evameelo@ hotmail.com
Wilson Antonio da Silva
ORCID: https://orcid.org/0000-0003-4174-3962
E-mail: wilson.antonio98@ @hotmail.com
Michelline Lins Silvério
Instituto Federal de Educação, Ciência e Tecnologia de Pernambuco, Brasil
ORCID: https://orcid.org/0000-0002-4715-0589
Centro Universitário São Miguel, Brasil
E-mail: chel_ls@ hotmail.com
Juliana Mendes Correia
ORCID: https://orcid.org/0000-0002-0093-9558
Centro Universitário São Miguel, Brasil
E-mail: mendescorre @yahoo.com.br

\section{Resumo}

O Brasil é o maior consumidor de agrotóxicos do mundo. A utilização desses pesticidas altera a composição da flora e da fauna, preservando os alimentos dos efeitos nocivos de alguns seres vivos. Porém, seu uso indiscriminado pode gerar danos à saúde humana e ao meio ambiente. O objetivo do presente estudo foi analisar os riscos causados ao homem pelo consumo de alimentos com resíduos de agrotóxicos. Trata-se de uma revisão de literatura do tipo integrativa, com buscas eletrônicas nas bases de dados Scielo (Scientific Electronic Library Online) e Biblioteca Virtual de artigos originais publicados nos últimos oito anos. Em relação aos agrotóxicos, o estudo verificou que, além da diversidade dos utilizados na produção de alimentos, muitos são manuseados de forma incorreta e em quantidades acima das permitidas. Os resíduos desses compostos são encontrados em diversos alimentos de origem vegetal presentes na mesa da maioria da população brasileira e podem causar efeitos nocivos, agudos ou crônicos, a depender do tipo de agrotóxico e do tempo de exposição ao mesmo. Diversas são as ações usadas para minimizar os efeitos dos agrotóxicos, como uma maior fiscalização na comercialização e no manuseio e o estímulo ao consumo de produtos orgânicos provenientes da agricultura familiar.

Palavras-chave: Agrotóxicos; Contaminação de alimentos; Resíduos; Agravos.

\begin{abstract}
Brazil is the largest consumer of pesticides in the world. The use of these pesticides alters the composition of flora and fauna, preserving food from the harmful effects of some living beings. However, its indiscriminate use can damage human health and the environment. The aim of the present study was to analyze the risks caused to man by the consumption of food with pesticide residues. It is an integrative literature review, with electronic searches in the Scielo (Scientific Electronic Library Online) and Virtual Library databases of original articles published in the last eight years. Regarding pesticides, the study found that, in addition to the diversity of those used in food production, many are handled incorrectly and in quantities above those allowed. The residues of these compounds are found in many foods of plant origin present on the table of the majority of the Brazilian population and can cause harmful effects, acute or chronic, depending on the type of pesticide and the time of exposure to it. There are several actions used to minimize the effects of pesticides, such as greater supervision in commercialization and handling and encouraging the consumption of organic products from family farming.
\end{abstract}

Keywords: Pesticides; Food contamination; Waste; Grievances.

\section{Resumen}

Brasil es el mayor consumidor de pesticidas del mundo. El uso de estos pesticidas altera la composición de la flora y la fauna, preservando los alimentos de los efectos nocivos de algunos seres vivos. Sin embargo, su uso indiscriminado puede causar daños a la salud humana y al medio ambiente. El objetivo del presente estudio fue analizar los riesgos 
que ocasiona al hombre el consumo de alimentos con residuos de plaguicidas. Se trata de una revisión integradora de la literatura, con búsquedas electrónicas en las bases de datos Scielo (Scientific Electronic Library Online) y Biblioteca Virtual de los artículos originales publicados en los últimos ocho años. En cuanto a los plaguicidas, el estudio encontró que, además de la diversidad de los que se utilizan en la producción de alimentos, muchos se manipulan incorrectamente y en cantidades superiores a las permitidas. Los residuos de estos compuestos se encuentran en diversos alimentos de origen vegetal presentes en la mesa de la mayoría de la población brasileña y pueden causar efectos nocivos, agudos o crónicos, según el tipo de plaguicida y el tiempo de exposición al mismo. Hay varias acciones que se utilizan para minimizar los efectos de los plaguicidas, como una mayor supervisión en la comercialización y manipulación y el fomento del consumo de productos orgánicos de la agricultura familiar.

Palabras clave: Plaguicidas; Contaminación alimenticia; Desperdicio; Quejas formales.

\section{Introdução}

A Lei $n^{\circ} 7.802$ de 11 de julho de 1989, regulamentada pelo Decreto ${ }^{\circ} 4.074$ de 04 de janeiro de 2002 (Brasil, 2002), trata os agrotóxicos como compostos físicos, químicos ou biológicos que têm por finalidade alterar a composição da flora ou da fauna para preservá-las das ações danosas de determinados seres vivos, como as pragas. Estes pesticidas são utilizados na agricultura, destinados aos setores de produção, armazenamento e beneficiamento de produtos. Possuem um grande potencial para atingir o solo e as águas e, independentemente de seu percurso, o principal receptor será o homem (Brasil, 2019).

O uso de agrotóxicos no Brasil iniciou-se na década de 1970 (Siqueira et al., 2013), com o Programa Nacional de Defensivos Agrícolas (PNDA). Os subsequentes avanços tecnológicos alavancaram a produção agrícola, resultando no rápido crescimento do mercado brasileiro de defensivos. Assim, desde 2008, o país é considerado o maior produtor e consumidor de agrotóxicos do mundo (Rigotto et al., 2014, Silva et al., 2018). Segundo a Fundação Oswaldo Cruz (2016), os principais fatores que contribuíram com este panorama foram: a escolha por um modelo de monoculturas voltado à exportação e uma série de políticas, com redução e isenção de impostos, incentivando cada vez mais o uso de pesticidas.

Herbicidas, inseticidas e fungicidas movimentam 95\% do consumo mundial de agrotóxicos, destacando-se no mercado brasileiro o herbicida glifosato (Braibante \& Zappe, 2012). De acordo com Pignati et al. (2017), os cultivos que mais consumiram agrotóxicos em 2015 foram a soja, o milho e a cana-de-açúcar, correspondendo a $82 \%$ de todo o consumo do país naquele ano.

Há poucos estudos a respeito da contaminação por agrotóxicos nos alimentos produzidos no Brasil, pois o processo de análise dos seus resíduos é oneroso e torna-se complexo devido às variáveis presentes nos produtos, como lipídeos, proteínas, carboidratos, pigmentos e umidade (Rumiato \& Monteiro, 2017). A grande maioria dos pesticidas tem a capacidade de acumular-se em diversos organismos, por se transformarem quimicamente e só desaparecerem depois de muitos anos, tornando-os tóxicos à saúde humana (Ismael et al., 2015).

Segundo o dossiê da Associação Brasileira de Saúde Coletiva (ABRASCO), 70\% dos alimentos in natura consumidos no país estão contaminados por agrotóxicos (Carneiro et al., 2015). As culturas que apresentam uma maior quantidade de resíduos de substâncias proibidas e fertilizantes são pimentão (92\%), morango (63\%) e pepino (57\%) (Anvisa, 2016).

A exposição prolongada aos resíduos de agrotóxicos nos alimentos pode desencadear efeitos agudos e levar a doenças como malformações congênitas, distúrbios neurológicos, câncer (Silva et al., 2011; Santos et al., 2014; Rumiato \& Monteiro, 2017), distúrbios endócrinos, alterações no desenvolvimento psicomotor, diabetes e obesidade (Meira \& Silva, 2019).

A Dose de Referência Aguda (DRfA) corresponde à quantidade estimada de resíduo de agrotóxico presente nos alimentos, ingerida em até 24 horas, sem causar efeito adverso à saúde, representada em miligrama de resíduo por quilograma de peso corpóreo $(\mathrm{mg} / \mathrm{kg})$. Geralmente é calculada quando há suspeita da presença de resíduos acima do Limite Máximo de Resíduos (LMR) (ANVISA, 2016).

Criado em 2001, o Programa de Análise de Resíduos de Agrotóxicos em Alimentos (PARA), uma ação do Sistema Nacional de Vigilância Sanitária (SNVS), tem como objetivo avaliar e promover a segurança dos alimentos quanto aos 
resíduos de agrotóxicos. Através de levantamento realizado entre 2013 e 2015, o Programa comprovou que 19,7\% das mais de 12.000 amostras de alimentos analisadas estavam em desacordo com a legislação e que 16,7\% desse percentual possuíam agrotóxicos não aprovados para uso na cultura. Além disso, 1,3\% continham resíduos de agrotóxicos acima do Limite Máximo de Resíduo (LMR) e 1,68\% apresentavam ambas as condições (ANVISA, 2016).

\section{Metodologia}

Trata-se de uma revisão integrativa qualitativa da literatura, realizada em bases científicas da área de saúde, seguindo as seguintes etapas: a) seleção da pergunta de pesquisa; b) busca na literatura; c) caracterização dos estudos; d) análise dos achados; e) interpretação dos resultados e f) síntese da revisão.

As bases de dados utilizadas nas buscas foram Scielo (Scientific Electronic Library Online) e Biblioteca Virtual em Saúde - BVS, considerando como critérios de inclusão: artigos originais publicados nos últimos oito anos, escritos em português e disponíveis na íntegra. Excluíram-se os artigos em língua estrangeira e em desacordo com o tema abordado. Um único artigo mais antigo, datado de 2005, foi incluído à pesquisa por conter informações imprescindíveis.

A seleção dos artigos ocorreu de acordo com as variáveis de interesse, utilizando os seguintes descritores: "agrotóxicos"; "agrotóxicos alimentação"; "contaminação de alimentos por agrotóxicos"; "resíduos de agrotóxicos"; "agravos por agrotóxicos"; "agrotóxicos no Brasil". Os artigos selecionados contemplam informações relevantes sobre a influência dos agrotóxicos na saúde humana.

\section{Resultados e Discussão}

\subsection{Agrotóxicos mais utilizados}

Devido à demanda aumentada de grãos, frutas e hortaliças, os agricultores têm sido estimulados a utilizarem uma variedade maior de produtos para reduzir perdas e aumentar a produtividade das safras. Isto consequentemente leva ao uso indiscriminado de químicos, colocando em risco a saúde de produtores e consumidores (Shinohara et al., 2017). Alguns estudos mostram os principais agrotóxicos utilizados na produção agrícola (Quadro 1).

Quadro 1 - Estudos sobre os agrotóxicos mais utilizados na produção agrícola brasileira.

\begin{tabular}{|l|l|l|}
\hline \multicolumn{2}{|c|}{ Tutores/ano } & \multicolumn{1}{|c|}{ Resultados da publicação } \\
\hline Pignati et al. & Distribuição espacial do uso de & Glifosato, Clorpirifós, 2,4-D, Atrazina, Mancozebe, Metoxifenozida, Acefato, \\
(2017) & $\begin{array}{l}\text { agrotóxicos no Brasil: uma } \\
\text { ferramenta para a Vigilância em } \\
\end{array}$ & $\begin{array}{l}\text { Haloxifope-P-Metílico, Lactofem, Metomil, Diquate, Picoxistrobina, } \\
\text { Flumetsulam, Teflubenzurom, Imidacloprido, Lambda cialotrina, Imazetapir, } \\
\text { Azoxistrobina e Flutriafol }\end{array}$ \\
\hline ONU (2018) & $\begin{array}{l}\text { Mudanças na lei de agrotóxicos no } \\
\text { Brasil violariam direitos humanos, } \\
\end{array}$ & Atrazina, Acefato, Carbendazim, Paraquat e Imidacloprida \\
\hline
\end{tabular}

Fonte: Autores (2020).

Segundo Pignati et al. (2017), dentre os agrotóxicos mais utilizados de 2012 a 2016, $15 \%$ apresentam-se extremamente tóxicos, $25 \%$ altamente tóxicos, $35 \%$ medianamente tóxicos e $25 \%$ pouco tóxicos, quanto ao risco para seres humanos. Segundo a ONU (2018), dos dez agrotóxicos mais utilizados no Brasil, cinco (Atrazina, Acefato, Carbendazim, Paraquat e Imidacloprida) não são autorizados em vários países por trazerem riscos à saúde humana e ao ecossistema. Especialistas da ONU ressaltaram que as leis brasileiras permitem níveis mais altos de exposição a pesticidas tóxicos do que as 
europeias: enquanto a União Europeia limita em $0,1 \mathrm{mg} \cdot \mathrm{L}^{-1}$ a quantidade máxima de glifosfato encontrado em água potável, o Brasil permite 5 mil vezes mais.

\subsection{Avaliação dos resíduos nos alimentos}

Um dos pontos preocupantes na saúde pública é a presença de resíduos acima dos níveis autorizados nos alimentos, decorrentes do uso crescente de agrotóxicos na produção agrícola (Shinohara et al., 2017). De acordo com a ANVISA (2016), resíduos dessas substâncias, autorizadas ou não, encontram-se presentes em diversos alimentos in natura e processados, como pães, pizzas, cereais, etc. No Quadro 2 são apresentados alguns desses compostos.

Quadro 2 - Resíduos de agrotóxicos mais encontrados nas amostras de alimentos.

\begin{tabular}{|c|c|c|}
\hline Autores/ano & Título da publicação & Resultados \\
\hline $\begin{array}{l}\text { Ismael et al. } \\
(2015)\end{array}$ & $\begin{array}{l}\text { Resíduos de agrotóxicos em alimentos: preocupação } \\
\text { ambiental e de saúde para população paraibana }\end{array}$ & $\begin{array}{l}\text { Metamidofós, Carbendazim, Acefato, Procloraz, } \\
\text { Bifentrina, Clotianidina e Esfenvalerato }\end{array}$ \\
\hline ANVISA (2016) & $\begin{array}{l}\text { Programa de Análise de Resíduos de Agrotóxicos em } \\
\text { Alimentos (PARA) }\end{array}$ & $\begin{array}{l}\text { Carbendazim, Acefato, Ditiocarbamatos } \\
\text { Tebuconazol }\end{array}$ \\
\hline $\begin{array}{l}\text { Ciscato e Gebara } \\
(2017)\end{array}$ & $\begin{array}{l}\text { Avaliação de resíduos de pesticidas na dieta Brasileira, } \\
\text { período de } 2001 \text { a } 2010\end{array}$ & Aldrim, $\mathrm{HCB}, \mathrm{HCH}$, Endossulfam e Ditiocarbamatos \\
\hline $\begin{array}{l}\text { Ferreira et al. } \\
(2018)\end{array}$ & $\begin{array}{l}\text { Estimativa de ingestão de agrotóxicos organofosforados pelo } \\
\text { consumo de frutas e hortaliças }\end{array}$ & $\begin{array}{l}\text { Metidationa, Metamidofós, Diazinona, Dicofol, } \\
\text { Dimetoato e Protiofós }\end{array}$ \\
\hline ANVISA (2019) & $\begin{array}{l}\text { Programa de Análise de Resíduos de Agrotóxicos em } \\
\text { Alimentos (PARA) }\end{array}$ & Imidacloprido, Tebuconazol e Carbendazim \\
\hline
\end{tabular}

Fonte: Autores (2020).

Dentre as substâncias relatadas por Ismael et al. (2015), Metamidofós e Carbendazim estão relacionadas à alta toxicidade aguda, encontradas em todas as amostras analisadas de pimentão. O Acefato, agrotóxico não autorizado para a cultura, foi detectado em três de oito amostras analisadas de cebola, consideradas insatisfatórias. Já Bifentrina, Procloraz, Clotianidina e Esfenvarelato foram encontradas nas amostras de abacaxi, consideradas com problemas. O agrotóxico que se destaca nas amostras analisadas pelo PARA (ciclo de 2013 a 2015) é o Carbendazim, detectado em 2.553 amostras, correspondendo a $21 \%$ das amostras analisadas nesse período. Destas, 327 foram consideradas insatisfatórias (ANVISA, 2016).

De acordo com estudo realizado por Ciscato e Gebara (2017), compostos organoclorados como Aldrim, HCB e HCH, encontrados nas amostras analisadas, têm uso proibido desde 1995, como assinala a Portaria nº 329, de 02 de setembro de 1985 (Brasil, 2020).

Ferreira et al. (2018) relataram que os agrotóxicos Metamidofós, Diazinona, Dicofol, Dimetoato, Protiofós e Metidationa excederam o parâmetro toxicológico de segurança para crianças. Já para adultos, os três que se enquadram em situação de risco humano são Dicofol, Metamidofós e Metidationa, todos avaliados através do consumo alimentar médio per capita nacional.

Como parâmetro mais recente tem-se um programa nacional de monitoramento, o Programa de Análise de Resíduos de Agrotóxicos em Alimentos (ANVISA, 2019), que analisou 4.616 amostras no ciclo de 2017/2018, pesquisando até 270 ingredientes ativos de agrotóxicos. Das amostras analisadas, foram detectados resíduos de 122 ingredientes ativos diferentes. Os maiores índices de detecção foram de Imidacloprido (16\%), Tebuconazol (12\%) e Carbendazim (11\%). 
A presença de diversos resíduos em uma mesma amostra pode ser explicada pela utilização de vários tipos de agrotóxicos contra uma diversidade de pragas e doenças. Ademais, algumas formulações contêm mais de um agrotóxico, que agem de formas diferentes no organismo alvo. Este tipo de estratégia é uma medida adotada no manejo integrado de pragas, a fim de minimizar sua resistência aos agrotóxicos. Outros motivos que levam à ocorrência de múltiplos resíduos em uma amostra são: o uso de agrotóxicos sem levar em consideração as Boas Práticas Agrícolas e a contaminação durante o manuseio, a embalagem e o armazenamento. Há uma preocupação quanto à deteç̧ão de vários resíduos em uma mesma amostra, devido à possibilidade de potencialização de efeitos adversos à saúde (ANVISA, 2016).

Segundo os dados coletados pelo Programa de Análise de Resíduos de Agrotóxicos em Alimentos (PARA) da ANVISA (2012), a partir de amostras oriundas das 26 Unidades Federativas do Brasil, um terço dos alimentos que consumimos está contaminado por agrotóxicos. Os alimentos mais contaminados estão listados na Tabela 1.

Tabela 1 - Ranking com os dez alimentos mais contaminados por agrotóxicos.

\begin{tabular}{|l|l|}
\hline Cultura & Amostras com resultados insatisfatórios* \\
\hline Pimentão & $91,8 \%$ \\
\hline Morango & $63,4 \%$ \\
\hline Pepino & $57,4 \%$ \\
\hline Alface & $54,2 \%$ \\
\hline Cenoura & $49,6 \%$ \\
\hline Abacaxi & $32,8 \%$ \\
\hline Beterraba & $32,6 \%$ \\
\hline Couve & $31,9 \%$ \\
\hline Mamão & $30,4 \%$ \\
\hline Tomate & $16,3 \%$ \\
\hline
\end{tabular}

*Porcentagem de amostras com nível de agrotóxico acima do tolerável. Fonte: ANVISA (2012). Fonte: Autores (2020).

\subsection{Riscos provenientes da exposição aos agrotóxicos}

Estes compostos químicos podem causar efeitos adversos à saúde humana, dependendo da forma, do tempo de exposição e do tipo de produto, além de sua toxicidade específica (Oliveira et al., 2013 \& Aguiar et al., 2019).

Segundo Ismael et al. (2015), devido à presença de resíduos acima dos níveis autorizados pelo uso crescente de agrotóxicos, a contaminação por vias indiretas, como a ingestão de alimentos, também está sendo um problema discutido e pesquisado na atualidade.

Um relatório da ANVISA, publicado em 30 de julho de 2019, atualizou o marco regulatório brasileiro de agrotóxicos, modernizando-o em relação aos aspectos relacionados à saúde, alinhando as normas brasileiras aos padrões internacionais observados na área. Uma dessas normas é a RDC no 295 de 2019, relacionada com a avaliação do risco dietético agudo e crônico decorrente da exposição humana a resíduos de agrotóxicos nos alimentos (ANVISA, 2019).

Alguns estudos mostram a distribuição espacial do uso de agrotóxicos e dos agravos à saúde humana (Quadro 3). 
Quadro 3 - Consequências e agravos à saúde decorrentes da exposição aos agrotóxicos.

\begin{tabular}{|c|c|c|}
\hline Autores/ano & Título da publicação & Resultados \\
\hline $\begin{array}{l}\text { Dutra e Ferreira } \\
\text { (2017) }\end{array}$ & $\begin{array}{l}\text { Associação entre malformações congênitas e a } \\
\text { utilização de agrotóxicos em monoculturas no } \\
\text { Paraná, Brasil }\end{array}$ & Alterações mãe-feto, como malformações congênitas \\
\hline $\begin{array}{l}\text { Lopes } \quad \mathrm{e} \\
\text { Albuquerque } \\
\text { (2018) }\end{array}$ & $\begin{array}{l}\text { Agrotóxicos e seus impactos na saúde humana e } \\
\text { ambiental: uma revisão sistemática }\end{array}$ & $\begin{array}{l}\text { Efeitos agudos como dor de cabeça, náuseas, dor de estômago, } \\
\text { ansiedade, irritabilidade, cólicas abdominais. Crônicos como } \\
\text { neoplasia cerebral, melanoma cutâneo, câncer de mama e nos } \\
\text { sistemas digestivo, urinário e respiratório }\end{array}$ \\
\hline $\begin{array}{l}\text { Oliveira et al. } \\
\text { (2014) }\end{array}$ & $\begin{array}{l}\text { Malformações congênitas em municípios de grande } \\
\text { utilização de agrotóxicos em Mato Grosso, Brasil }\end{array}$ & Efeitos no desenvolvimento humano, como malformações fetais \\
\hline $\begin{array}{lll}\text { Santos } & \text { et } a l . \\
(2014) & \end{array}$ & $\begin{array}{l}\text { Avaliação da inserção de alimentos orgânicos } \\
\text { provenientes da agricultura familiar na alimentação } \\
\text { escolar, em municípios dos territórios rurais do Rio } \\
\text { Grande do Sul, Brasil }\end{array}$ & $\begin{array}{l}\text { Efeitos crônicos como câncer, malformações congênitas, } \\
\text { distúrbios endócrinos, neurológicos }\end{array}$ \\
\hline
\end{tabular}

Fonte: Autores (2020).

Algumas consequências e agravos agudos ou crônicos à saúde podem estar relacionados à exposição direta aos agrotóxicos, como no caso dos agricultores. De acordo com Lopes e Albuquerque (2018), os danos variam desde dores de cabeça, ansiedade, irritabilidade, náuseas e dor de estômago a alterações crônicas, associadas a exposições prolongadas, como câncer cerebral, digestivo, mamário, esofágico, respiratório e urinário, além de melanoma. Para Dutra e Ferreira (2017), os agrotóxicos também podem estar relacionados a malformações congênitas, fato corroborado por Oliveira et al. (2014).

Contudo, além dos efeitos causados pela exposição direta, há os indiretos, causados pela exposição aos resíduos de agrotóxicos encontrados em alimentos. Tais consequências ainda não estão totalmente elucidadas pela ciência, porém, segundo Santos et al. (2014), algumas alterações podem ser desencadeadas em meses, anos ou décadas, manifestando-se em câncer, malformações congênitas, distúrbios neurológicos e endócrinos.

Existem diversos desafios a serem enfrentados quanto à análise mais detalhada dos danos causados pelos agrotóxicos à saúde humana. A formulação de indicadores de saúde com dados de intoxicação por agrotóxicos é um deles, devido ao aumento da subnotificação destes agravos. De acordo com Pignati et al. (2017), para cada caso de intoxicação aguda registrado, outros 50 não são notificados.

\section{Considerações Finais}

O uso crescente de agrotóxicos e seus impactos à saúde, sejam agudos ou crônicos, vêm sendo percebidos. Sabe-se também que, na produção de alimentos em grande escala, é indispensável o uso consciente desses compostos para não resultar em baixas produtividades ou perdas de culturas decorrentes de pragas e doenças. No entanto, faz-se necessária uma maior fiscalização na comercialização e no manuseio desses produtos, a fim de evitar problemas toxicológicos tanto para o homem quanto para o meio ambiente.

Algumas soluções já vêm surgindo para a diminuição desses agravos tóxicos. Em 16 de junho de 2020, o Ministério da Agricultura, Pecuária e Abastecimento (MAPA) publicou o registro de dois defensivos agrícolas bioquímicos inéditos. Um deles tem como base Cerevisane, produto bioquímico derivado de um agente biológico de baixo impacto, que pode ser utilizado como indutor de resistência contra a ferrugem da soja. O outro é um fungicida bioquímico feito de um extrato da alga Laminaria digitata, a ser utilizado em hortaliças (alface, tomate e cebola) e frutas (morango e uva). 
Quanto ao consumo dos vegetais, deve-se levar em consideração a sua procedência, optando pelos que tenham a origem identificada. Uma forma de minimizar os efeitos dos agrotóxicos presentes em vegetais é a lavagem correta dos alimentos e a retirada de cascas e folhas externas, pois ajudam na redução de resíduos presentes apenas na superfície.

De acordo com a ANVISA, optar por orgânicos e sazonais são procedimentos para obter um produto livre de agrotóxicos. O estímulo desses alimentos, além de favorecer a diminuição dos riscos provocados pelos resíduos de agrotóxicos, valoriza o pequeno produtor na compra de alimentos básicos e locais, incentivando a agricultura familiar.

A população deve ter acesso à informação mais ampliada acerca dos efeitos desses contaminantes na saúde. É importante que o consumidor comece a questionar o que consome, modificando seus hábitos alimentares, na medida do possível, para uma alimentação saudável, com alimentos orgânicos, produzidos até por si mesmo em hortas caseiras.

Diante do trabalho exposto, é relevante ressaltar a importância de mais pesquisas relacionadas ao tema. São necessários estudos que explorem a temática da exposição crônica alimentar, a fim de garantir uma proteção mais segura aos agravos advindos dos agrotóxicos. Também são interessantes pesquisas que exponham o aumento desordenado da liberação de agrotóxicos, muitos não regulamentados pela ANVISA, representando um risco à saúde humana e ambiental, além daquelas que relatem a importância de uma alimentação baseada em alimentos orgânicos, pois são ferramentas fundamentais para a promoção da saúde.

\section{Referências}

Aguiar, A. F. et al. (2019). Sistema de registro do agrotóxico no Brasil. Alomorfia, Presidente Prudente-SP, 3(1), 49-60.

ANVISA. (2016). Agência Nacional de Vigilância Sanitária. Programa de Análise de Resíduos de Agrotóxicos em Alimentos- PARA: relatório das análises de amostras monitoradas no período de 2013 a 2015. https://www.gov.br/anvisa/pt-br/assuntos/agrotoxicos/programa-de-analise-de-residuos-emalimentos/arquivos/3778json-file-1.

ANVISA. (2012) Agência Nacional de Vigilância Sanitária. http://portal.anvisa.gov.br/wps/content/anvisa+portal/anvisa/sala+de+imprensa/menu++noticias+anos/2012+noticias/seminario+volta+a+discutir+mercado+de+agrotoxicos+em+2012.

ANVISA. (2019). Agência Nacional de Vigilância Sanitária. Programa de Análise de Resíduos de Agrotóxicos em Alimentos- PARA: relatório das amostras analisadas no período de 2017-2018. https:/www.gov.br/anvisa/pt-br/centraisdeconteudo/publicacoes/agrotoxicos/programa-de-analise-de-residuos-deagrotoxicos-relatorio-2017-e-2018.pdf/view.

Braibante, M. E. F., \& Zappe, J. A. (2012) A química dos agrotóxicos. Química Nova na Escola, 34(1), 10-15.

Brasil. (2002). Decreto $\mathrm{n}^{\circ}$ 4.074, de 4 de janeiro de 2002. Regulamenta a Lei $\mathrm{n}^{\circ}$ 7.802, de 11 de julho de 1989. Presidência da República, 2002. http://www.planalto.gov.br/ccivil_03/decreto/2002/D4074.htm\#art98.

Brasil. (2019). Ministério do Meio Ambiente. Segurança Química. Brasília, DF: Ministério do Meio Ambiente. http://www.mma.gov.br/segurancaquimica/gestao-das-substancias/produtos-agrotoxicos.

Brasil. (2020). Convenção de Estocolmo. CETESB - Centro Regional. https://cetesb.sp.gov.br/centroregional/a-convencao.

Carneiro, F. F. et al. (2015). Dossiê ABRASCO: um alerta sobre os impactos dos agrotóxicos na saúde. Rio de Janeiro: EPSJV; Expressão Popular.

Ciscato, C. H. P., \& Gebara, A. B. (2017). Avaliação de resíduos de pesticidas na dieta brasileira, período de 2001 a 2010. Higiene Alimentar, 31 , $274 / 275$.

Dutra, L. S., \& Ferreira, A. P. (2017). Associação entre malformações congênitas e a utilização de agrotóxicos em monoculturas no Paraná, Brasil. Saúde Debate, 41, 241-253.

Ferreira, V. B. et al. (2018). Estimativa de ingestão de agrotóxicos organofosforados pelo consumo de frutas e hortaliças. Cadernos Saúde Coletiva, 26(2), $216-221$.

FIOCRUZ. (2016). Oficina online debate os impactos do uso de agrotóxicos no Brasil. Rio de Janeiro. http://portal.fiocruz.br/noticia/oficina-online-debate-osimpactos-do-uso-de-agrotoxicos-no-brasil.

Ismael, L. L. et al. (2015). Resíduos de agrotóxicos em alimentos: preocupação ambiental e de saúde para população paraibana. Revista Verde, 10(3), 24-29.

Lopes, C. V. A., \& Albuquerque, G. S. C. (2018). Agrotóxicos e seus impactos na saúde humana e ambiental: uma revisão sistemática. Saúde Debate, 42(117), $518-534$.

Meira, A. P. G., \& Silva, M. V. (2019). Resíduos de agrotóxicos potencialmente contidos na dieta habitual de escolares. Segurança Alimentar e Nutricional, $26,1-12$. 
Research, Society and Development, v. 10, n. 6, e36110614504, 2021

(CC BY 4.0) | ISSN 2525-3409 | DOI: http://dx.doi.org/10.33448/rsd-v10i6.14504

Oliveira, T. G., Favareto, A. P. A., \& Antunes, P. A. (2013). Agrotóxicos: Levantamento dos mais utilizados no Oeste Paulista e seus efeitos como Desreguladores Endócrinos. IX Fórum Ambiental da Alta Paulista. Saúde, Saneamento e Meio Ambiente. 9(11), 375-390.

Oliveira, N. P. et al. (2014). Malformações congênitas em municípios de grande utilização de agrotóxicos em Mato Grosso, Brasil. Ciência \& Saúde Coletiva 19(10), 4123-4130.

ONU. (2018). Organização das Nações Unidas para a Alimentação e a Agricultura - Brasil. Mudanças na lei de agrotóxicos no Brasil violariam direitos humanos, afirmam relatores da ONU. Brasília, DF. https://brasil.un.org/pt-br/80507-mudancas-na-lei-de-agrotoxicos-no-brasil-violariam-direitos-humanosafirmam-relatores-da-onu.

Pignati, W. A. et al. (2017). Distribuição espacial do uso de agrotóxicos no Brasil: uma ferramenta para a Vigilância em Saúde. Ciência \& Saúde Coletiva, 22(10), 3281-3293.

Rigotto, R. M., Vasconcelos, D. P., \& Rocha, M. M. (2014). Uso de agrotóxicos no Brasil e problemas para a saúde pública. Caderno Saúde Pública, 30(7), 13 .

Rumiato, A. C., \& Monteiro, I. (2017). Contaminantes em alimentos e orientação nutricional: reflexão teórica. Revista de Salud Pública, 19(4), $574-577$.

Santos, F. et al. (2014). Avaliação da inserção de alimentos orgânicos provenientes da agricultura familiar na alimentação escolar, em municípios dos territórios rurais do Rio Grande do Sul, Brasil. Ciência \& Saúde Coletiva, 19(5), 1429-1436.

Shinohara, N. K. S. et al. (2017). Insegurança alimentar no uso indiscriminado de agrotóxicos. Higiene Alimentar, 31, 266/267.

Silva, S. R. G., et al. (2011). Defeitos congênitos exposição a agrotóxicos no Vale do São Francisco. Rev. Brás. Ginecologia e Obstetrícia. $33(1)$, $20-26$.

Silva, L. C. B. et al. (2018). Influência dos agrotóxicos na alimentação infantil. Revista Dissertar, 1(28 e 29), 23-32.

Siqueira, D. F. et al. (2013). Análise da exposição de trabalhadores rurais a agrotóxicos. Revista Brasileira em Promoção da Saúde, 26(2), $182-191$. 